\title{
Simulation and measurement of water- induced liquid-liquid phase separation of imidazolium ionic liquid mixtures
}

Cite as: J. Chem. Phys. 149, 164503 (2018); https://doi.org/10.1063/1.5054786

Submitted: 03 September 2018 . Accepted: 09 October 2018 . Published Online: 29 October 2018

M. Alejandra Rocha (D), Yong Zhang, Edward J. Maginn (D), and Mark B. Shiflett (D)
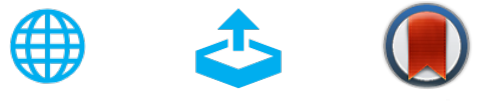

\section{ARTICLES YOU MAY BE INTERESTED IN}

Nanoscale domains in ionic liquids: A statistical mechanics definition for molecular dynamics studies

The Journal of Chemical Physics 149, 184502 (2018); https://doi.org/10.1063/1.5054999

The activation energy for water reorientation differs between IR pump-probe and NMR measurements

The Journal of Chemical Physics 149, 164504 (2018); https://doi.org/10.1063/1.5050203

Perspective: Dynamics of confined liquids

The Journal of Chemical Physics 149, 170901 (2018); https://doi.org/10.1063/1.5057759

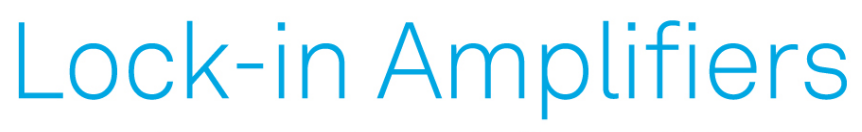

... and more, from DC to $600 \mathrm{MHz}$ Watch 


\title{
Simulation and measurement of water-induced liquid-liquid phase separation of imidazolium ionic liquid mixtures
}

\author{
M. Alejandra Rocha, ${ }^{1}$ Yong Zhang, ${ }^{2}$ Edward J. Maginn, ${ }^{2}$ and Mark B. Shiflett ${ }^{1}$ \\ ${ }^{1}$ Department of Chemical and Petroleum Engineering, University of Kansas, Lawrence, Kansas 66045, USA \\ ${ }^{2}$ Department of Chemical and Biomolecular Engineering, University of Notre Dame, Notre Dame, \\ Indiana 46556, USA
}

(Received 3 September 2018; accepted 9 October 2018; published online 29 October 2018)

\begin{abstract}
The miscibility of ionic liquid (IL) pairs with a common cation (1-ethyl-3-methylimidazolium $\left[\mathrm{C}_{2} \mathrm{C}_{1} \mathrm{im}\right]$ ) and different anions (bis(trifluoromethylsulfonyl)amide [TFSI], acetate [OAc], and chloride $[\mathrm{Cl}]$ ) was investigated at a wide range of water concentrations at room temperature. Molecular simulations predicted that the addition of water to the $\left[\mathrm{C}_{2} \mathrm{C}_{1} \mathrm{im}\right][\mathrm{TFSI}]:\left[\mathrm{C}_{2} \mathrm{C}_{1} \mathrm{im}\right][\mathrm{OAc}]$ and $\left[\mathrm{C}_{2} \mathrm{C}_{1}\right.$ im $][\mathrm{TFSI}]:\left[\mathrm{C}_{2} \mathrm{C}_{1} \mathrm{im}\right][\mathrm{Cl}]$ mixtures would induce a liquid-liquid phase separation and that water addition to the $\left[\mathrm{C}_{2} \mathrm{C}_{1} \mathrm{im}\right][\mathrm{OAc}]:\left[\mathrm{C}_{2} \mathrm{C}_{1} \mathrm{im}\right][\mathrm{Cl}]$ mixture would not produce a phase separation. The effect of water on the phase behavior of the IL mixtures was verified experimentally, and the IL and water concentrations were determined in each phase. Of particular importance is the analytical methodology used to determine the species' concentration, where ${ }^{1} \mathrm{H}$ NMR and a combination of ${ }^{19} \mathrm{~F}$ NMR, Karl Fischer titration, and ion chromatography techniques were applied. Published by AIP Publishing. https://doi.org/10.1063/1.5054786
\end{abstract}

Ionic liquids (ILs) have been intensely investigated in recent years due to their many favorable properties. ${ }^{1}$ One of the most attractive features of ILs is that their physical properties can be adjusted by varying the identity and structure of the cation and anion. Recent work has shown that properties of ILs can be further fine-tuned by mixing ILs. ${ }^{2-6}$ While in many cases the ILs are miscible, mixtures containing hydrophilic and hydrophobic ions have been shown to give rise to two distinct immiscible phases, ${ }^{7}$ which has implications for separation processes. ${ }^{8,9}$ Miscibility of these ILs has been found to be temperature dependent such that a biphasic system is present at low temperature, but at high temperature the ILs are completely miscible. ${ }^{7}$ ILs have also been shown to form two aqueous-rich liquid phases when mixed with water and a "salting out" or kosmotropic inorganic salt such as $\mathrm{K}_{3} \mathrm{PO}_{4} \cdot{ }^{10}$ These aqueous biphasic systems (ABSs) have been intensely studied for over a decade, ${ }^{11}$ and have been found to be useful for liquid-liquid extraction of proteins, drug molecules, and dyes. ${ }^{12,13}$ ABSs composed of only two ILs and water were first reported by the Ohno group, ${ }^{14}$ but less is known about these systems.

Herein, we demonstrate that miscible mixtures of two ionic liquids having a common cation (1-ethyl-3methylimidaziolium or $\left[\mathrm{C}_{2} \mathrm{C}_{1} \mathrm{im}\right]$ ) and different anions of varying hydrophilicity (chloride $[\mathrm{Cl}]$, acetate $[\mathrm{OAc}]$, and bis(trifluoromethylsulfonyl)amide [TFSI]) can be induced to separate into two liquid phases by the simple addition of water. One phase is rich in water and contains the cation and a predominance of the more hydrophilic anion, while the other phase is water-lean and contains the cation and a predominance of the more hydrophobic anion. We find that 1:1 molar mixtures of [Cl:TFSI] and [OAc:TFSI] exhibit this phase separation, while 1:1 molar mixtures containing [Cl:OAc] remain one phase at all water compositions.
This finding was first predicted by molecular dynamics simulations. Equimolar ionic liquid mixtures were modeled by placing $800\left[\mathrm{C}_{2} \mathrm{C}_{1} \mathrm{im}\right]$ cations in a simulation box along with 400 of one type of anion and 400 of another type of anion. Anion mixtures of [Cl:OAc], [Cl:TFSI], and [OAc:TFSI] were modeled at $293 \mathrm{~K}$. Simulation details are provided in the supplementary material. When no water was present, each IL mixture was miscible, showing no signs of phase separation [Figs. 1(a) and 1(c)]. Upon the addition of 1200 water molecules $(x=0.60)$, the [OAc:TFSI] system began to show signs of phase separation, while the [OAc: $\mathrm{Cl}]$ system remained one phase. When more water was added (4000 molecules, $\mathrm{x}=0.83$ ), clear liquid-liquid phase separation was observed in the [OAc:TFSI] system [Fig. 1(b)], while the [OAc:Cl] system remained miscible [Fig. 1(d)]. The simulations also predicted that the [Cl:TFSI] system phase separates into two liquid phases upon the addition of water (see the supplementary material), with $[\mathrm{Cl}]$ going to the water-rich phase and [TFSI] going to a separate phase with less water.

Figure 1 clearly shows that the simulations predict that the cations and anions are uniformly dispersed throughout the liquid in the dry systems. When water is added to the [OAc:TFSI] system, the $[\mathrm{OAc}]$ anions segregate to the water-rich phase, while the more hydrophobic [TFSI] anions partition to the water-lean phase. To maintain charge neutrality, the $\left[\mathrm{C}_{2} \mathrm{C}_{1} \mathrm{im}\right]$ cations remain homogenously distributed between the two phases. For the mixture containing [OAc:Cl], both anions are hydrophilic and there is no preference for either of them to partition with water; water equally solvates both anions, and a single liquid phase is maintained at all water concentrations.

To test the simulation predictions experimentally, equimolar mixtures of these three ionic liquid systems were placed in borosilicate glass tubes and small amounts of water were slowly added at room temperature until a meniscus appeared. 
a)
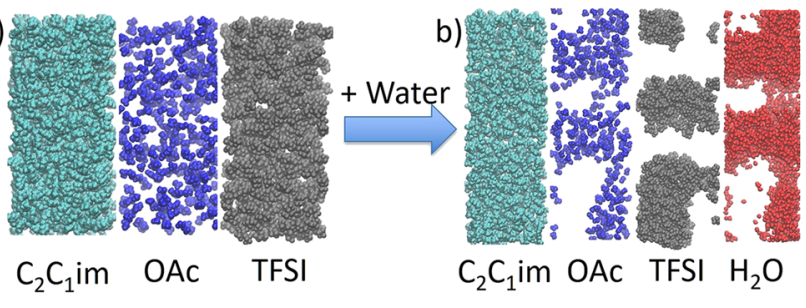

$\mathrm{C}_{2} \mathrm{C}_{1}$ im OAC TFSI $\mathrm{H}_{2} \mathrm{O}$

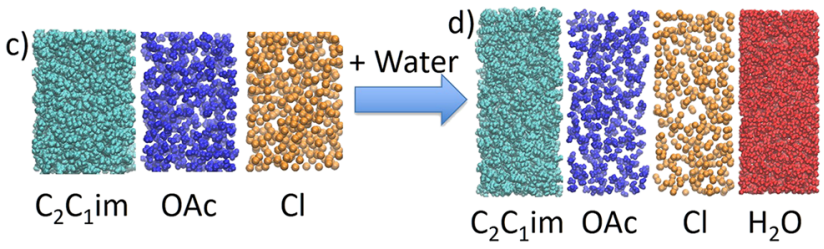

FIG. 1. Final snapshots from molecular dynamics simulations showing that the (a) dry $\left[\mathrm{C}_{2} \mathrm{C}_{1} \mathrm{im}\right][\mathrm{OAc}: \mathrm{TFSI}]$ and (c) dry $\left[\mathrm{C}_{2} \mathrm{C}_{1} \mathrm{im}\right][\mathrm{OAc}: \mathrm{Cl}]$ systems are miscible, but upon attaining $\mathrm{x}=0.83$ ( $83 \mathrm{~mol} \%$ water), the OAc:TFSI (b) system phase separates into water-rich and water-lean phases, while the $\mathrm{OAc:Cl}$ system (d) remains one phase. Each panel shows only $\left[\mathrm{C}_{2} \mathrm{C}_{1} \mathrm{im}\right]$ (cyan), [OAc] (blue), [TFSI] (gray), [Cl] (gold), or water (red).

Each liquid phase was analyzed to determine the concentration of individual components.

At initial and low water concentrations, the 1:1 mole ratio $\left[\mathrm{C}_{2} \mathrm{C}_{1}\right.$ im] $[\mathrm{TFSI}]:\left[\mathrm{C}_{2} \mathrm{C}_{1}\right.$ im $][\mathrm{OAc}]$ mixture remained homogeneous as shown in Figs. 2(a) and 2(b). As water was initially added to the system, cloudiness was observed at points of contact between the ILs and water, and a noticeable amount of heat was released, resulting in a temperature increase which we estimate to be less than $10 \mathrm{~K}$. This heat can be attributed to the exothermic process of hydrogen bonding between water and the acetate ions. ${ }^{15,16}$ Gradual additions of water to the equimolar IL solution resulted in a liquid phase split, observed at $54 \pm 2$ mol. $\% \mathrm{H}_{2} \mathrm{O}$, as shown in Fig. 2(c).

Each liquid phase was weighed, sampled, and analyzed with a quantitative NMR approach. The applied NMR technique determines species concentrations by calculating relative peak integral ratios and has been previously used in the literature ${ }^{17}$ to determine unknown concentrations of bi-phasic solutions. In our study, this method was successfully applied using ${ }^{1} \mathrm{H}$ NMR to estimate the phase concentrations of the $\left[\mathrm{C}_{2} \mathrm{C}_{1} \mathrm{im}\right][\mathrm{TFSI}],\left[\mathrm{C}_{2} \mathrm{C}_{1} \mathrm{im}\right][\mathrm{OAc}]$, and $\mathrm{H}_{2} \mathrm{O}$ mixture, as $\left[\mathrm{C}_{2} \mathrm{C}_{1} \mathrm{im}\right]$, [OAc] , and $\mathrm{H}_{2} \mathrm{O}$ have clear proton peaks and integral representations. The concentration of [TFSI] was determined by difference as explained in the supplementary material. The analysis revealed that the top liquid phase was water-rich and the bottom liquid phase was rich in $\left[\mathrm{C}_{2} \mathrm{C}_{1}\right.$ im] [TFSI], as shown in Fig. 2(d) and Table I. The study also determined that the top phase had a higher concentration of $\left[\mathrm{C}_{2} \mathrm{C}_{1} \mathrm{im}\right][\mathrm{OAc}]$ as reported in Fig. 2(d). These results are reasonable as the $[\mathrm{OAc}]$ anion has a higher affinity for water than the [TFSI] anion, and the density of $\left[\mathrm{C}_{2} \mathrm{C}_{1} \mathrm{im}\right][\mathrm{TFSI}]$ is greater than that of water and $\left[\mathrm{C}_{2} \mathrm{C}_{1} \mathrm{im}\right][\mathrm{OAc}]$. Therefore, the majority of $\left[\mathrm{C}_{2} \mathrm{C}_{1} \mathrm{im}\right][\mathrm{TFSI}]$ was present in the bottom liquid phase. It was assumed that the $\left[\mathrm{C}_{2} \mathrm{C}_{1} \mathrm{im}\right]$ cations were distributed among both phases, according to the concentration of each anion, to maintain neutrality in each phase. Water content in each phase was also analyzed by Karl Fischer (KF) volumetric titration, and the results were within $1 \%$ of the water mass

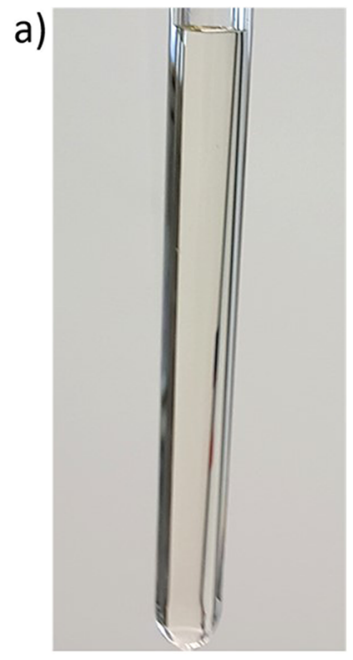

d)
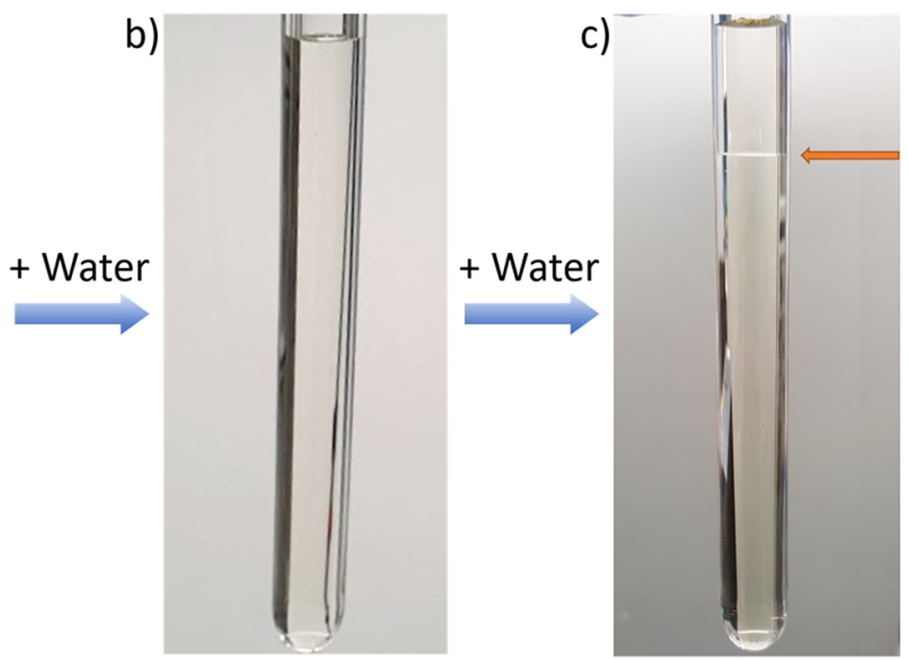

\section{${ }^{1} \mathrm{H}$ NMR}

(mole\%)

\section{${ }^{1} \mathrm{H}$ NMR}

(mass \%)

\section{Karl Fischer \\ (mass \%)}

\section{$\left[\mathrm{C}_{2} \mathrm{C}_{1} \mathrm{im}\right][\mathrm{TFSI}] \quad 5.50 \pm 1.57 \% \quad 28.41 \pm 5.83 \%$}

Top $\left[\mathrm{C}_{2} \mathrm{C}_{1}\right.$ im] $[\mathrm{OAc}] \quad 24.42 \pm 1.11 \% 54.91 \pm 4.59 \%$ $\mathrm{H}_{2} \mathrm{O}$ $70.08 \pm 1.54 \%$

$16.68 \pm 1.44 \%$

$\left[\mathrm{C}_{2} \mathrm{C}_{1}\right.$ im] [TFSI] $34.77 \pm 1.50 \% 76.45 \pm 1.20 \%$

Bot. $\left[\mathrm{C}_{2} \mathrm{C}_{1}\right.$ im] $[\mathrm{OAc}]$

$$
\mathrm{H}_{2} \mathrm{O}
$$

$19.82 \pm 1.25 \% 18.95 \pm 1.15 \%$

$45.41 \pm 1.21 \%$

$4.60 \pm 0.20 \%$

Measured

Calculated

from NMR

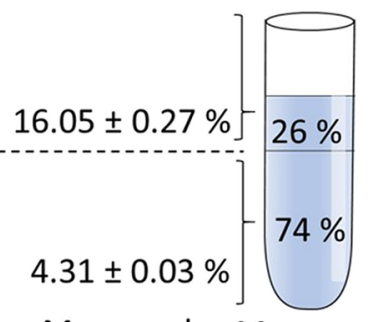

Measured Measured

by KF by Mass*
FIG. 2. The equimolar solution of $\left[\mathrm{C}_{2} \mathrm{C}_{1} \mathrm{im}\right][\mathrm{TFSI}]$ and $\left[\mathrm{C}_{2} \mathrm{C}_{1} \mathrm{im}\right][\mathrm{OAc}]$ at $\mathrm{T}=295 \pm 1 \mathrm{~K}$ was (a) a homogeneous liquid phase at initial water content of $2.3 \pm 1.2 \mathrm{~mol}$. \%, (b) remained homogenous when the water content increased to $50 \pm 1 \mathrm{~mol} \%$, and (c) phase split at $54 \pm 2 \mathrm{~mol}$. \% water. (Orange arrow indicates the meniscus.) (d) The phase concentrations were determined by ${ }^{1} \mathrm{H}$ NMR, and Karl Fischer (KF) was used to confirm water content. "Top" refers to the top phase, and "Bot." refers to the bottom phase, as shown in 2(c). * The measured weight percentages in each phase were $26.16 \% \pm 0.15 \%$ on the top and $73.84 \% \pm 0.15 \%$ on the bottom. 
TABLE I. Phase partition results (in wt. \%) for the $\left[\mathrm{C}_{2} \mathrm{C}_{1}\right.$ im][TFSI]: $\left[\mathrm{C}_{2} \mathrm{C}_{1}\right.$ im $][\mathrm{OAc}]: \mathrm{H}_{2} \mathrm{O}$ mixture.

\begin{tabular}{lcc}
\hline \hline Component & Top phase $(\%)$ & Bottom phase $(\%)$ \\
\hline$\left[\mathrm{C}_{2} \mathrm{C}_{1}\right.$ im] $[\mathrm{TFSI}]$ & $11.15 \pm 2.42$ & $88.85 \pm 2.42$ \\
$\left[\mathrm{C}_{2} \mathrm{C}_{1}\right.$ im] $\left.] \mathrm{OAc}\right]$ & $49.45 \pm 4.16$ & $50.55 \pm 4.16$ \\
$\mathrm{H}_{2} \mathrm{O}$ & $55.05 \pm 4.03$ & $44.95 \pm 4.03$ \\
\hline \hline
\end{tabular}

concentrations obtained using ${ }^{1} \mathrm{H}$ NMR, as shown in Fig. 2(d). Furthermore, the NMR results were used to estimate the overall mass phase partition, which resulted in the top and bottom phases containing $25.24 \pm 2.47$ wt. $\%$ and $74.76 \pm 2.47 \mathrm{wt} . \%$ of the total mass, respectively. These results were within $1 \%$ of the actual measured phase partitions $(26.16 \pm 0.15 \mathrm{wt}$. \% in the top phase and $73.84 \pm 0.15 \mathrm{wt} . \%$ in the bottom phase) reported in Fig. 2(d).

In addition, the liquid-liquid equilibrium temperature dependence was observed. The two-phase mixture was heated in intervals of $5 \mathrm{~K}$ beginning at $298.15 \pm 0.30 \mathrm{~K}$ and sequentially agitated and allowed to settle to identify the condition at which the meniscus disappeared (as described in the supplementary material). At $303.11 \pm 0.30 \mathrm{~K}$, the mixture returned to a single-phase system.

The second system in this study was the equimolar $\left[\mathrm{C}_{2} \mathrm{C}_{1} \mathrm{im}\right][\mathrm{TFSI}]$ and $\left[\mathrm{C}_{2} \mathrm{C}_{1} \mathrm{im}\right][\mathrm{Cl}]$ mixture. The $\left[\mathrm{C}_{2} \mathrm{C}_{1} \mathrm{im}\right][\mathrm{Cl}]$ is present in the form of green-colored crystals at $295 \mathrm{~K}$. Color in ionic liquids can originate from the presence of trace metal impurities. Measurements with inductively coupled plasma mass spectrometry (ICP-MS) determined the $\left[\mathrm{C}_{2} \mathrm{C}_{1} \mathrm{im}\right][\mathrm{Cl}]$ contained $90-130 \mathrm{ppm} \mathrm{Ni}$. The anhydrous salt nickel(II) chloride $\left(\mathrm{NiCl}_{2}\right)$ is known to be yellow and the more familiar hydrate $\mathrm{NiCl} \cdot 6 \mathrm{H}_{2} \mathrm{O}$ is green. However, the trace levels of metal hydrate will have no effect on the liquid-liquid equilibria (LLE) measurements. When $\left[\mathrm{C}_{2} \mathrm{C}_{1}\right.$ im] $[\mathrm{TFSI}]$ and $\left[\mathrm{C}_{2} \mathrm{C}_{1} \mathrm{im}\right][\mathrm{Cl}]$ were initially combined, they remained in a heterogeneous solid-liquid solution as shown in Fig. 3(a), until the concentration of water was increased to about $20 \mathrm{~mol}$ \% . At this stage, all the $\left[\mathrm{C}_{2} \mathrm{C}_{1} \mathrm{im}\right][\mathrm{Cl}]$ had dissolved and the mixture was a homogeneous green color. This color persisted as the system partitioned into a two-phase mixture at $39 \pm 3 \mathrm{~mol} . \%$ $\mathrm{H}_{2} \mathrm{O}$ as shown in Fig. 3(c), indicating that $\left[\mathrm{C}_{2} \mathrm{C}_{1} \mathrm{im}\right][\mathrm{Cl}]$ is present in both phases, though not necessarily at the same concentration.

The determination of the species concentration in each liquid phase required multiple analysis techniques. First, the mass of each layer was measured, and the volume was calculated as explained in the supplementary material. Quantitative ${ }^{19} \mathrm{~F}$ NMR analysis was applied to estimate the concentration of $\left[\mathrm{C}_{2} \mathrm{C}_{1} \mathrm{im}\right][\mathrm{TFSI}]$ in each liquid layer. The NMR method was performed using an external fluorine standard in a coaxial tube to prevent the ionic liquid mixture and the standard solution from interacting. The volume effects in the NMR analysis were corrected as described by Henderson ${ }^{18}$ and are detailed in the supplementary material. Quantitative analysis by ${ }^{1} \mathrm{H}$ NMR was more difficult due to concentration effects and poor peak deconvolution. For this reason, the only method used to measure water concentration was Karl Fischer. To verify the mass balance, $\left[\mathrm{C}_{2} \mathrm{C}_{1} \mathrm{im}\right][\mathrm{Cl}]$ content was measured using ion chromatography (IC) (see the supplementary material for more details).

The ${ }^{19} \mathrm{~F}$ NMR, IC, and KF results were used to estimate the mass percent of each phase to be $16.69 \pm 1.47$ wt. \% in the top phase and $83.31 \pm 1.47 \mathrm{wt} \%$ in the bottom phase. The estimations were only about two percent different from the actual measured masses for each phase $(14.93 \pm 0.06 \mathrm{wt} . \%$ in the top phase and $85.07 \pm 0.06 \mathrm{wt} . \%$ in the bottom phase); see Fig. 3(d). In addition, the results

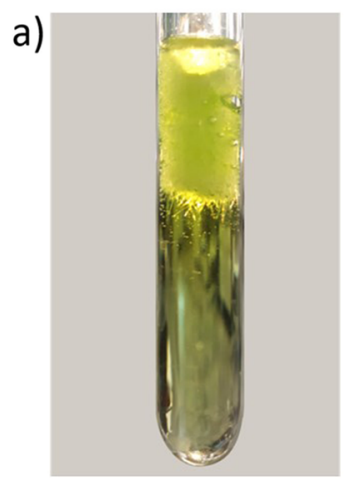

d)

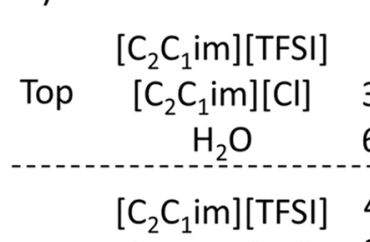

Bot.

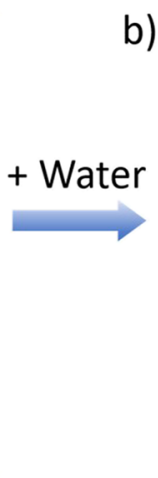

Mole \%

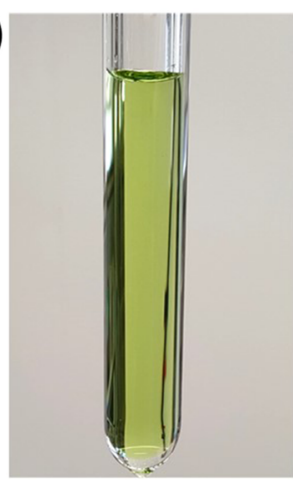

Mass \%

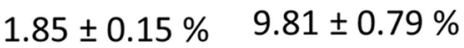

$38.08 \pm 0.66 \% 75.54 \pm 0.53 \%$ $60.07 \pm 0.69 \% 14.65 \pm 0.40 \%$ $48.75 \pm 2.64 \% 82.88 \pm 8.73 \%$ $23.47 \pm 1.21 \% 14.95 \pm 0.05 \%$ $\left[\mathrm{C}_{2} \mathrm{C}_{1} \mathrm{im}\right][\mathrm{Cl}]$ $\mathrm{H}_{2} \mathrm{O}$
$27.78 \pm 1.46 \%$

$2.17 \pm 0.03 \%$

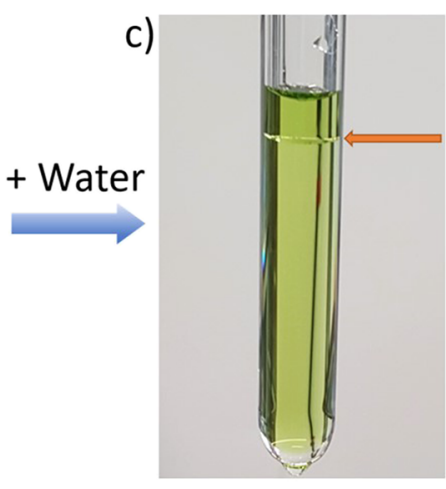

Techniques

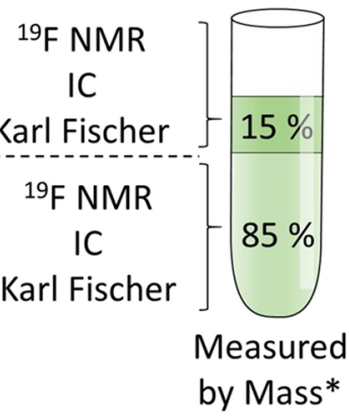

by Mass*
FIG. 3. Equimolar mixture of $\left[\mathrm{C}_{2} \mathrm{C}_{1}\right.$ im $][\mathrm{TFSI}]$ and $\left[\mathrm{C}_{2} \mathrm{C}_{1} \mathrm{im}\right][\mathrm{Cl}]$ with increasing concentration of water at $295 \pm 1 \mathrm{~K}$. The initial system was (a) a heterogeneous mixture (solid-liquid solution) containing $2.1 \pm 2.0 \mathrm{~mol} . \%$ $\mathrm{H}_{2} \mathrm{O}$ and became (b) a homogenous liquid at $20 \pm 1 \mathrm{~mol} \% \mathrm{H}_{2} \mathrm{O}$. As more water was added, (c) the system partitioned into two-liquid phases at $39 \pm 3$ mol. $\% \mathrm{H}_{2} \mathrm{O}$. (Orange arrow indicates the meniscus.) A variety of analytical techniques (NMR, IC, and $\mathrm{KF})$ were applied to determine the species concentrations in each phase, as shown in (d). "Top" refers to the top phase, and "Bot." refers to the bottom phase, as shown in $3(\mathrm{c}){ }^{*}$ The measured weight percentages in each phase were $14.93 \% \pm 0.06 \%$ on the top and $85.07 \% \pm 0.06 \%$ on the bottom. Measured

Calculated 
TABLE II. Phase partition results (in wt. \%) for the $\left[\mathrm{C}_{2} \mathrm{C}_{1}\right.$ im][TFSI]: $\left[\mathrm{C}_{2} \mathrm{C}_{1}\right.$ im $][\mathrm{Cl}]: \mathrm{H}_{2} \mathrm{O}$ mixture.

\begin{tabular}{lrc}
\hline \hline Component & Top phase $(\%)$ & Bottom phase (\%) \\
\hline$\left[\mathrm{C}_{2} \mathrm{C}_{1}\right.$ im] $[\mathrm{TFSI}]$ & $2.32 \pm 0.18$ & $97.68 \pm 0.18$ \\
{$\left[\mathrm{C}_{2} \mathrm{C}_{1}\right.$ im] $[\mathrm{Cl}]$} & $50.30 \pm 2.64$ & $49.70 \pm 2.64$ \\
$\mathrm{H}_{2} \mathrm{O}$ & $57.43 \pm 2.69$ & $42.57 \pm 2.69$ \\
\hline \hline
\end{tabular}

in Fig. 3(d) and Table II show that the top liquid phase was water rich and the bottom phase was rich in $\left[\mathrm{C}_{2} \mathrm{C}_{1} \mathrm{im}\right][\mathrm{TFSI}]$. Similar to the $\left[\mathrm{C}_{2} \mathrm{C}_{1} \mathrm{im}\right][\mathrm{TFSI}]:\left[\mathrm{C}_{2} \mathrm{C}_{1} \mathrm{im}\right][\mathrm{OAc}]: \mathrm{H}_{2} \mathrm{O}$ system, it was expected that the bottom phase would be rich in $\left[\mathrm{C}_{2} \mathrm{C}_{1} \mathrm{im}\right][\mathrm{TFSI}]$, and the top phase would be rich in water with a higher concentration of the hydrophilic ionic liquid. Temperature effects were also tested in the [Cl]:[TFSI] mixture, which was heated in $5 \mathrm{~K}$ intervals beginning at $298.15 \pm 0.30 \mathrm{~K}$ and agitated until the two-phase meniscus disappeared at $323.11 \pm 0.30 \mathrm{~K}$.

Both room temperature systems $\left[\mathrm{C}_{2} \mathrm{C}_{1}\right.$ im $][\mathrm{TFSI}]$ : $\left[\mathrm{C}_{2} \mathrm{C}_{1}\right.$ im $][\mathrm{OAc}]: \mathrm{H}_{2} \mathrm{O}$ and $\left[\mathrm{C}_{2} \mathrm{C}_{1}\right.$ im $][\mathrm{TFSI}]:\left[\mathrm{C}_{2} \mathrm{C}_{1}\right.$ im $][\mathrm{Cl}]$ : $\mathrm{H}_{2} \mathrm{O}$ exhibited a liquid-liquid phase separation with the addition of water. The mole ratio of $\mathrm{H}_{2} \mathrm{O}:[\mathrm{OAc}]$ in the top phase was 2.87:1 and 2.29:1 in the bottom phase, while the mole ratio of $\mathrm{H}_{2} \mathrm{O}:[\mathrm{Cl}]$ was $1.58: 1$ in the top phase and 1.18:1 in the bottom phase. This behavior is consistent with the water-[OAc] and water- $[\mathrm{Cl}]$ interactions in the top phase and with the repulsive hydrophobic interactions of the [TFSI] anion with water in the bottom phase.

The third system investigated was the $1: 1$ mole ratio mixture of $\left[\mathrm{C}_{2} \mathrm{C}_{1} \mathrm{im}\right][\mathrm{Cl}]$ and $\left[\mathrm{C}_{2} \mathrm{C}_{1} \mathrm{im}\right][\mathrm{OAc}]$. The solution was initially a heterogeneous solid-liquid mixture with no water added [Fig. 4(a)], similar to the [TFSI]:[Cl] system, as $\left[\mathrm{C}_{2} \mathrm{C}_{1} \mathrm{im}\right][\mathrm{Cl}]$ is a solid at room temperature. When the system reached $43 \pm 1 \mathrm{~mol} . \% \mathrm{H}_{2} \mathrm{O}$, the $\left[\mathrm{C}_{2} \mathrm{C}_{1} \mathrm{im}\right][\mathrm{Cl}]$ dissolved and the solution became light green in color [Fig. 4(b)]. More water was added to the system, until the water concentration was $83.6 \pm 0.1 \mathrm{~mol} \%$. Heat was released as the solution was mixed, and the color changed to an amber-like tint, as shown in Fig. 4(c). No liquid-liquid separation was observed at room temperature. This phase behavior is consistent with the molecular dynamics simulations and is expected, as both anions are hydrophilic and have similar dimensions. Considering [OAc] and [Cl] have comparable van der Waals radii of $1.6 \AA^{19}$ and $1.75 \AA{ }^{20}$ respectively, it can be concluded that the anions share similar charge densities and are equally miscible with water.

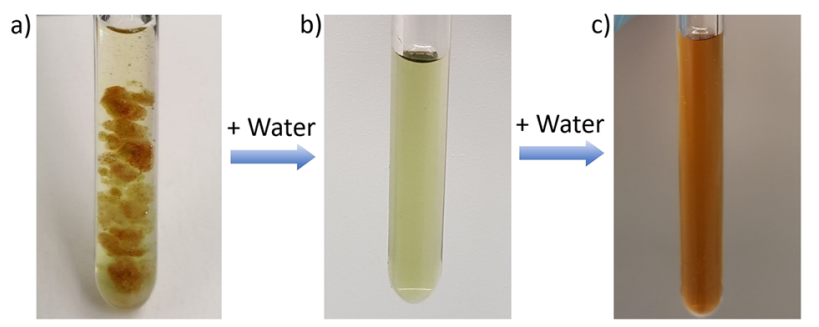

FIG. 4. Progression of equimolar mixture of $\left[\mathrm{C}_{2} \mathrm{C}_{1}\right.$ im $][\mathrm{OAc}]:\left[\mathrm{C}_{2} \mathrm{C}_{1} \mathrm{im}\right][\mathrm{Cl}]$ as water increases from (a) $3.9 \pm 1.3 \mathrm{~mol} . \%$, to (b) $43 \pm 1 \mathrm{~mol} . \%$ and (c) $83.6 \pm 0.1 \mathrm{~mol} . \%$.

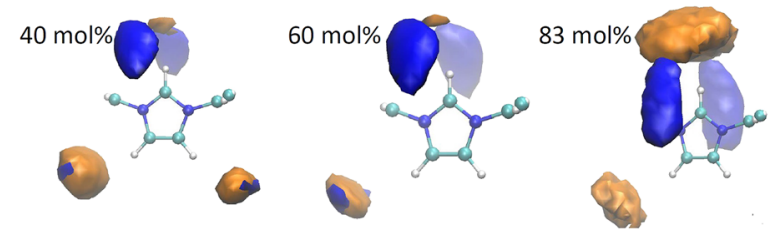

FIG. 5. Spatial distribution function for [OAc] (blue) and [Cl] (orange) around $\left[\mathrm{C}_{2} \mathrm{C}_{1} \mathrm{im}\right]$ in equimolar mixtures of $\left[\mathrm{C}_{2} \mathrm{C}_{1} \mathrm{im}\right][\mathrm{OAc}]$ and $\left[\mathrm{C}_{2} \mathrm{C}_{1} \mathrm{im}\right][\mathrm{Cl}]$. The water mole fractions are labeled in the figures. The iso-density surfaces were drawn at $80 \%$ of the maximum density in each case.

Previous literature has shown that a color change in imidazolium based ionic liquids with $[\mathrm{Cl}]$ anions is due to the thermal decomposition of the ionic liquid. ${ }^{21,22}$ However, the present study indicates that the color change occurs at room temperature when the $\mathrm{H}_{2} \mathrm{O}$ to $\left[\mathrm{C}_{2} \mathrm{C}_{1} \mathrm{im}\right][\mathrm{Cl}]$ ratio is increased from 1.5:1 to 10:1. To understand this color change, the liquid structure in these mixtures was studied by creating spatial distribution functions (SDFs) from the molecular dynamics simulations. The results for $[\mathrm{OAc}]$ and $[\mathrm{Cl}]$ around a central $\left[\mathrm{C}_{2} \mathrm{C}_{1} \mathrm{im}\right]$ are shown in Fig. 5. At $40 \mathrm{~mol} . \%$ and $60 \mathrm{~mol} . \%$ $\mathrm{H}_{2} \mathrm{O}$, [OAc] prefers to stay close to the $\mathrm{C} 2$ position of $\left[\mathrm{C}_{2} \mathrm{C}_{1} \mathrm{im}\right]$ and locates on both sides of the imidazolium ring. On the other hand, $[\mathrm{Cl}]$ locates close to the $\mathrm{C} 4$ and $\mathrm{C} 5$ positions, with less intensity on the $\mathrm{C} 5$ side due to repulsion from the cation ethyl group. At 83 mol. $\% \mathrm{H}_{2} \mathrm{O}$, the solvation structure dramatically changes: $[\mathrm{Cl}]$ is now most likely to be found on top of the $\mathrm{C} 2$ carbon and has a slightly lower probability around $\mathrm{C} 4$. On the other hand, [OAc] is still close to $\mathrm{C} 2$ but is clearly pushed further to the sides of the imidazolium ring. It is very likely that the color change observed in experiments is related to these solvation structure changes when the $\mathrm{H}_{2} \mathrm{O}$ mol. \% was increased from $60 \%$ to $83 \%$. Further studies are needed to verify this behavior.

In summary, evidence of a water-induced liquid-liquid phase separation of ionic liquid mixtures having a common $\left[\mathrm{C}_{2} \mathrm{C}_{1} \mathrm{im}\right]$ cation but pairs of anions with different degrees of hydrophilicity ([Cl]-[TFSI] and [OAc]-[TFSI]) was observed in molecular dynamics simulations. The simulations also predicted that an ionic liquid mixture containing the $\left[\mathrm{C}_{2} \mathrm{C}_{1} \mathrm{im}\right]$ cation with equimolar amounts of hydrophilic anions ([Cl] and $[\mathrm{OAc}]$ ) would remain one phase at all water concentrations. All three of these predictions were subsequently confirmed experimentally. Quantitative concentration measurements were made for each phase using a combination of NMR, IC, and KF. In addition, a color change from pale green to amber was observed upon the addition of water to the $\left[\mathrm{C}_{2} \mathrm{C}_{1} \mathrm{im}\right][\mathrm{OAc}]:\left[\mathrm{C}_{2} \mathrm{C}_{1} \mathrm{im}\right][\mathrm{Cl}]$ mixture. At such water concentrations, the simulations depict an abrupt change in the distribution of $[\mathrm{Cl}]$ ions about the $\left[\mathrm{C}_{2} \mathrm{C}_{1} \mathrm{im}\right]$ cation, and therefore suggest a possible reason for the color variation.

See supplementary material for the following: simulation details including computational approach and force fields; experimental details including materials, procedures, and error calculation.

We acknowledge Dr. David Minnick for providing directions on the mixture content analysis, Dr. Justin T. Douglas 
and Sarah Neuenswander for their assistance in running NMR samples, and Rasha Faraj for performing the ion chromatography analysis. Y.Z. and E.J.M. acknowledge the support by the U.S. Department of Energy, Basic Energy Science, Joint Center for Energy Storage Research under Contract No. DE-AC0206CH11357 and the Air Force Office of Scientific Research under Contract No. AFOSR FA9550-18-10321. Computational resources were provided by the Center for Research Computing (CRC) at the University of Notre Dame.

${ }^{1} \mathrm{P}$. Wasserscheid and T. Welton, Ionic Liquids in Synthesis, 2nd ed. (Wiley-VCH, 2008).

${ }^{2}$ H. Niedermeyer, J. P. Hallett, I. J. Villar-Garcia, P. A. Hunt, and T. Welton, Chem. Soc. Rev. 41, 7780 (2012).

${ }^{3}$ M. T. Clough, C. R. Crick, J. Gräsvik, P. A. Hunt, H. Niedermeyer, T. Welton, and O. P. Whitaker, Chem. Sci. 6, 1101 (2015).

${ }^{4}$ C. P. Cabry, L. D'Andrea, K. Shimizu, I. Grillo, P. Li, S. E. Rogers, D. W. Bruce, J. N. C. Lopes, and J. M. Slattery, Faraday Discuss. 206, 265 (2017).

${ }^{5}$ J. M. Andanson, M. J. Beier, and A. Baiker, J. Phys. Chem. Lett. 2, 2959 (2011).

${ }^{6}$ R. P. Matthews, I. J. Villar-Garcia, C. C. Weber, J. Griffith, F. Cameron, J. P. Hallett, P. A. Hunt, and T. Welton, Phys. Chem. Chem. Phys. 18, 8608 (2016).

${ }^{7}$ A. Arce, M. J. Earle, S. P. Katdare, H. Rodríguez, and K. R. Seddon, Chem. Commun. 2, 2548 (2006).
${ }^{8}$ C. M. S. S. Neves, A. M. S. Silva, A. M. Fernandes, J. A. P. Coutinho, and M. G. Freire, J. Phys. Chem. Lett. 8, 3015 (2017).

${ }^{9}$ M. C. Castro, A. Arce, A. Soto, and H. Rodríguez, J. Chem. Thermodyn. 102, 12 (2016).

${ }^{10}$ K. E. Gutowski, G. A. Broker, H. D. Willauer, J. G. Huddleston, R. P. Swatloski, J. D. Holbrey, and R. D. Rogers, J. Am. Chem. Soc. 125, 6632 (2003).

${ }^{11}$ M. G. Freire, A. F. M. Cláudio, J. M. M. Araújo, J. A. P. Coutinho, I. M. Marrucho, J. N. C. Lopes, and L. P. N. Rebelo, Chem. Soc. Rev. 41, 4966 (2012).

${ }^{12}$ S. Y. Lee, I. Khoiroh, C. W. Ooi, T. C. Ling, and P. L. Show, Sep. Purif. Rev. 46, 291 (2017).

${ }^{13}$ A. Dimitrijevic, T. Trtić-Petrović, M. Vraneš, S. Papović, A. Tot, S. Dožić, and S. Gadžuric, J. Chem. Eng. Data 61, 549 (2016).

${ }^{14}$ Y. Kohno and H. Ohno, Phys. Chem. Chem. Phys. 14, 5063 (2012).

${ }^{15}$ K. A. Le, R. Sescousse, and T. Budtova, Cellulose 19, 45 (2012).

${ }^{16}$ S. V. Troshenkova, E. S. Sashina, N. P. Novoselov, and K.-F. Arndt, Russ. J. Gen. Chem. 80, 501 (2010).

${ }^{17}$ A. Arce, O. Rodríguez, and A. Soto, Chem. Eng. Sci. 61, 6929 (2006).

${ }^{18}$ T. J. Henderson, Anal. Chem. 74, 191 (2002).

${ }^{19}$ C. S. Lovell, A. Walker, R. A. Damion, A. Radhi, S. F. Tanner, T. Budtova, and M. E. Ries, Biomacromolecules 11, 2927 (2010).

${ }^{20}$ A. Bondi, J. Phys. Chem. 68, 441 (1964).

${ }^{21}$ T. Jiang, M. J. Chollier Brym, G. Dubé, A. Lasia, and G. M. Brisard, Surf. Coat. Technol. 201, 1 (2006).

${ }^{22}$ S. Carda-Broch, A. Berthod, and D. W. Armstrong, Anal. Bioanal. Chem. 375, 191 (2003). 